\title{
A New Fungicide Produced by a Streptomyces sp. GAAS7310
}

\author{
Guangying Chen, Birun Lin, Yongcheng Lin, Fengchun Xie, Wen Lu, Wang-Fun Fong
}

Received: April 22, 2005 / Accepted: July 16, 2005

(C) Japan Antibiotics Research Association

\begin{abstract}
Directed bioassay guided fraction led to a new macrodiolide antimycin $\mathrm{A}_{17}$ (1), isolated from a Streptomyces sp. GAAS7310, which showed significant antimicrobial activity against eleven fungal species, including Curvularia lunata (Wakker) Boed, Rhizopus nigrtcans Ehrb and Colletotrichum nigrum EL. et Halst. The structure was unambiguously established by interpretation of 1D and 2D NMR data and comparison with the known antimycin $A_{1 a}$.
\end{abstract}

Keywords Streptomyces sp.; antimycin; antimicrobial activity; fungicide; macrodiolide; actinomycete

\section{Introduction}

Actinomycetes are prolific producers of antibiotics and other industrially useful secondary metabolites [1 5]. Because these metabolites are often active against a limited number of specific target species, biodegradable to nontoxic products, and potentially suitable for use in integrated management programs, they can lead to the development of new classes of safer disease control agents. In our course of screening for novel naturally occurring fungicides from actinomycetes, the acetone extract of the mycelium of a Streptomycetes sp. 7310\# collected at Tianshan mountain was found to have strong activity against 12 fungal strains, e.g. Phomopsis vexans (Sacc et Syd) Harter etc. By bioassay guided fractionation, we isolated a new macrodiolide, antimycin $\mathrm{A}_{17}$ (1), which showed activity against several fungi. Among these fungi,

G. Chen: Department of Chemistry, Hainan Normal University, Haikou 571158, People's Republic of China

Y. Lin (Corresponding author), W. Lu: Department of Applied Chemistry, Zhongshan University, Guangzhou 510275, People's Republic of China, E-mail: yclin48@hotmail.com
Curvularia lunata (Wakker) Boed, Rhizopus nigrtcans Ehrb and Colletotrichum nigrum EL. et Halst were more sensitive to antimycin $\mathrm{A}_{17}$ (1).

\section{Materials and Methods}

\section{General Experimental Procedure}

Melting point was determined on a XT-4 apparatus and was uncorrected. NMR spectra were recorded on a Varian Inova-500 NMR spectrometer $(500 \mathrm{MHz})$ using acetone- $d_{6}$ as solvent and TMS as an internal standard. Mass spectra were measured on a VG-ZAB-HS analytical spectrometer. IR spectra were taken on a Nicolet 5DX-FTIR spectrophotometer. Optical rotation was determined in acetone at room temperature using a Horiba High Sensitivity SEPA-300 Polarimeter, and elemental analysis was recorded on an Elementar Vario EL CHNS-O elemental analysis device. Preparative HPLC were performed on an Waters 2695 system equipped with an autosampler, a quaternary pump system, a photodiode array detector, and a Chemstation data system. A $250 \mathrm{~mm} \times$ $20 \mathrm{~mm}$ i.d., $5 \mu \mathrm{m}$ particle size Zorbax Eclipse XDB ODS column (Agilent) was selected for HPLC preparation. Analytical thin-layer chromatography (TLC) was carried out on precoated silica gel aluminum plates (Merck, 60 $\mathrm{F}_{254}, 0.2 \mathrm{~mm}$ thickness) and HPTLC plates (Merck, RP-18). Silica gel (200 300 mesh, Qingdao Haiyang Chemical Co., Ltd.), RP-18 silica gel (50 $\mu \mathrm{m}$, Merck), and CAD-45 absorber resin (26 60 mesh, Anhui Sanxing resin technology Co., Ltd.), were used for column

B. Lin, F. Xie: Institute of Plant-protect, Guangdong Academy of Agricultural Science, Guangzhou 510000, People's Republic of China

G. Chen, W.-F. Fong: Department of Biology \& Chemistry, City University of Hong Kong, Hong Kong 
chromatography. The solvents used for high-performance liquid chromatography (HPLC) were of HPLC grade (Sigma); and other solvents and chemicals were of analytical grade.

\section{Collection and Cultivation}

The bacterium Streptomyces sp. GAAS7310 was isolated from the soil collected at Tianshan mountain, Xinjiang Province, P.R. China. It has been deposited in the China Center for Type Culture Collection (CCTCC), Wuhan, P.R. China. Deposited number was CCTCC M 203058 Streptomyces sp. GAAS7310. Starter cultures were maintained on cornmeal agar. Plugs of agar supporting mycelial growth were cut and transferred aseptically into $250 \mathrm{ml}$ Erlenmeyer flasks containing $100 \mathrm{ml}$ of liquid medium (starch $1 \%$, calcium carbonate $0.2 \%$, ammonium sulfate $0.2 \%$, potassium dihydrogen phosphate $0.1 \%$, magnesium bisulfate $0.1 \%$, sodium chloride $0.1 \%$, yeast extract $1 \%, \mathrm{pH} 7.2$ ). The content were incubated at $28^{\circ} \mathrm{C}$ on a rotary shaker for $5 \sim 7$ days, and the mycelium was aseptically transferred to a 500-liter fermentor containing the same culture liquid (300 liters) with the following settings: air, 1.8 liters/minute; impellor speed, $200 \mathrm{rpm}$ for 3 days.

\section{Extraction and Isolation}

The 300-liter culture was filtered through Celite to separate the mycelium and culture liquid. The acetone extract of mycelium exhibited the strong activity against twelve fungal species. The $85 \%$ aqueous acetone extract of $900 \mathrm{~g}$ mycelium was adsorbed onto a macroporous resin (CAD-45, $50 \mathrm{~cm} \times 9 \mathrm{~cm}$ i.d.), followed by on elution with water, then ethyl acetate respectively. The ethyl acetate fraction was evaporated in vacuum at $45^{\circ} \mathrm{C}$ and yielded $15 \mathrm{~g}$ pale-yellow oil, then subjected to column chromatography over silica gel (200 g, 200 300 mesh, $80 \mathrm{~cm} \times 3.5 \mathrm{~cm}$ i.d.) and eluted with petrol (bp $60 \sim 90^{\circ} \mathrm{C}$ )EtOAc mixtures of increasing $10 \%$ polarity, The $30 \%$ fraction showed strong fungicidal acitivities. This fraction $(1.5 \mathrm{~g})$ was further purified by means of a silica gel column $(80 \mathrm{~g}, \quad 200 \sim 300$ mesh, $\quad 50 \mathrm{~cm} \times 2.5 \mathrm{~cm} \quad$ i.d. $)$ using chloroform/methanol $(95: 5)$ as the solvent system to yield a bioactive mixture. Further purified by HPLC (a $250 \mathrm{~mm} \times 20 \mathrm{~mm}$ i.d., $5 \mu \mathrm{m}$ particle size Zorbax Eclipse XDB ODS column) with methanol/water $(70: 30)$ as the mobile phase to yield the active component 1 (retention time 15.1 minutes, $25 \mathrm{mg}$ ). The molecular structure of compound 1 was elucidated by means of mass, IR, and 1D and 2D NMR spectroscopic techniques as the new macrodiolide antimycin $\mathrm{A}_{17}$.

Compound 1: colorless crystalline solid (65 mg). mp
$140 \sim 142^{\circ} \mathrm{C} .[\alpha]_{\mathrm{D}}^{20}+114.7$ (c 0.002 , acetone); IR (KBr) $v_{\max }: 3350,2960,1797,1742,1679,1638,1532,1455$, 1367, 1252, 1178, 1075, $875 \mathrm{~cm}^{-1} ;{ }^{1} \mathrm{H}$ and ${ }^{13} \mathrm{C}$ NMR (see Table 1); FAB-MS $m / z$ : $535(\mathrm{M}+\mathrm{H})^{+}, 521,492,451,372$, 265, 164, 107, 102; Anal. (\%): found C 60.75, H 7.15, N 5.25, O 26.85; calcd. C 60.66, H 7.16, N 5.24, O 26.9.

\section{Fungicidal Activity In Vitro}

Antifungal activities of antimycin $\mathrm{A}_{17}$ were investigated by disk assay method, using twelve representative fungi. These fungi were grown in potato dextrose agar (PDA) media, at $28^{\circ} \mathrm{C}$. The PDA plates were prepared with antimycin $\mathrm{A}_{17}$ (at a concentration of $100 \mu \mathrm{g} / \mathrm{ml})$. Then, disks $(6.0 \mathrm{~mm}$ in diameter) of epiphyte were placed on the plates. Similarly, disks of epiphyte were also placed on the innocuous plates (adding the same dosage sterile water) as blank comparison. All plates were incubated at $28^{\circ} \mathrm{C}$ for $1 \sim 3$ days. Each fungus had five repeats. The results are shown in Table 2. Among these fungi, $R$. nigrtcans, Cladosporium sp. and C. nigrum were most sensitive.

\section{Results and Discusion}

The acetone extract of the mycelium was adsorbed by CAD-45, followed by washing with water and EtOAc successively. The EtOAc extract was concentrated in vacuo, then chromatographed on silica gel column and RP-HPLC as monitored by bioassay against fungi. This afforded the active compound antimycin $\mathrm{A}_{17}(\mathbf{1})$ and no other antimycins were obtained.

The molecular formula of $\mathbf{1}$ was determined to be $\mathrm{C}_{27} \mathrm{H}_{38} \mathrm{~N}_{2} \mathrm{O}_{9}$ by elemental analysis and FABMS data. UV absorptions at 328 and $212 \mathrm{~nm}$ were assigned to a chromophore with extended conjunction. Analysis of the ${ }^{13} \mathrm{C}$ NMR spectrum (Table 1) showed five carbonyl carbon signals $(\delta 175.7,174.1,170.9,170.3,160.7)$, six olefinic carbon signals $(\delta 151.6,128.6,125.2,122.6,119.3,114.5)$. These accounted for eight of the ten degrees of unsaturation required by the molecular formula, therefore illustrating compound $\mathbf{1}$ to be bicyclic.

The ${ }^{1} \mathrm{H}$ NMR signals at $\delta 8.47(1 \mathrm{H}, \mathrm{dd}, J=8,1.5 \mathrm{~Hz}, \mathrm{H}-$ $\left.6^{\prime}\right), \delta 7.77\left(1 \mathrm{H}, \mathrm{dd}, J=8,1.5 \mathrm{~Hz}, \mathrm{H}-4^{\prime}\right)$ and $\delta 6.92(1 \mathrm{H}, \mathrm{dd}$, $\left.J=8,8 \mathrm{~Hz}, \mathrm{H}-5^{\prime}\right)$ indicated the presence of an orthotrisubstituted benzene ring. In the $\mathrm{H}-\mathrm{H}$ COSY, the proton correlations of $\mathrm{NH}-3^{\prime}$ and $\mathrm{H}-8^{\prime}$, and in the HMBC the correlations of the proton of $\mathrm{NH}-3^{\prime}$ and $\mathrm{C}-8^{\prime}$ suggested the presence of a $\mathrm{NH}-\mathrm{CHO}$ moiety. A pentyl side chain was revealed by the contiguous correlations from $\mathrm{H}-12$ to $\mathrm{H}-16$ in ${ }^{1} \mathrm{H}-{ }^{1} \mathrm{H}$ COSY and correlations from $\mathrm{H}-12$ to $\mathrm{C}-6$ and $\mathrm{C}-7$ in HMBC. A contiguous sequence from $\mathrm{H}-18$ to $\mathrm{H}-20$ and 
Table 1 NMR data of antimycin $A_{17}$ (actone- $d_{6}$, TMS)

\begin{tabular}{|c|c|c|c|c|}
\hline No. & ${ }^{13} \mathrm{C}$ & ${ }^{1} \mathrm{H}$ (mult, J) & COSY & $\mathrm{HMBC}$ \\
\hline 2 & 170.3 & & & \\
\hline 3 & 54.7 & $5.41(\mathrm{dd}, 8.0,7.0 \mathrm{~Hz})$ & $\mathrm{NH}-3, \mathrm{H}-4$ & 2,4 \\
\hline 4 & 72.2 & $5.70(\mathrm{dq}, 7.0,7.0 \mathrm{~Hz})$ & $\mathrm{H}-3, \mathrm{H}-11$ & 2,6 \\
\hline 6 & 174.1 & & & \\
\hline 7 & 51.1 & $2.55(\mathrm{~m})$ & $\mathrm{H}-8$ & 6,12 \\
\hline 8 & 76.3 & $5.0(\mathrm{~m})$ & $\mathrm{H}-7,9$ & 6,17 \\
\hline 9 & 74.8 & $4.9(\mathrm{~m})$ & $\mathrm{H}-8, \mathrm{H}-10$ & $2,8,10$ \\
\hline 10 & 18.2 & $1.30(\mathrm{~d}, 7.0 \mathrm{~Hz})$ & $\mathrm{H}-9$ & 8,9 \\
\hline 11 & 15.4 & $1.40(\mathrm{~d}, 7.0 \mathrm{~Hz})$ & $\mathrm{H}-4$ & 3,4 \\
\hline 12 & 29.7 & $1.29(\mathrm{~m}), 1.63(\mathrm{~m})$ & $\mathrm{H}-13,7$ & 6,7 \\
\hline 13 & 23.1 & $0.95(\mathrm{~m}), 1.12(\mathrm{~m})$ & $\mathrm{H}-12,14$ & 15 \\
\hline 14 & 36.7 & $1.28(\mathrm{~m})$ & $\mathrm{H}-13,15$ & 16 \\
\hline 15 & 28.6 & $1.21(\mathrm{~m})$ & $\mathrm{H}-14,16$ & \\
\hline 16 & 13.9 & $0.86(t, 7.0 \mathrm{~Hz})$ & & \\
\hline 17 & 175.7 & & & \\
\hline 18 & 41.8 & $2.47(\mathrm{~m})$ & $\mathrm{H}-19,21$ & 19,20 \\
\hline 19 & 27.2 & $1.51(\mathrm{~m}), 1.74(\mathrm{~m})$ & $\mathrm{H}-18,20$ & 17,18 \\
\hline 20 & 11.9 & $1.16(t, 7.0 \mathrm{~Hz})$ & $\mathrm{H}-19$ & \\
\hline 21 & 17.0 & $1.17(\mathrm{~d}, 7.0 \mathrm{~Hz})$ & $\mathrm{H}-18$ & 17,18 \\
\hline $1^{\prime}$ & 114.5 & & & \\
\hline $2^{\prime}$ & 151.6 & & & \\
\hline $3^{\prime}$ & 128.6 & & & \\
\hline $4^{\prime}$ & 125.2 & $8.47(\mathrm{dd}, 8.0,1.5 \mathrm{~Hz})$ & $\mathrm{H}-5^{\prime}$ & $2^{\prime}, 6^{\prime}$ \\
\hline $5^{\prime}$ & 119.3 & $6.92(\mathrm{dd}, 8.0,8.0 \mathrm{~Hz})$ & $\mathrm{H}-4^{\prime}, 6^{\prime}$ & $1^{\prime}, 3^{\prime}, 4^{\prime}, 6^{\prime}$ \\
\hline $6^{\prime}$ & 122.6 & $7.77(\mathrm{dd}, 8.0,1.5 \mathrm{~Hz})$ & $\mathrm{H}-5^{\prime}$ & $2^{\prime}, 4^{\prime}, 5^{\prime}, 7^{\prime}$ \\
\hline $7^{\prime}$ & 170.9 & & & \\
\hline $8^{\prime}$ & 160.7 & $8.52(\mathrm{~d}, 1.5 \mathrm{~Hz})$ & $3^{\prime}-\mathrm{NH}$ & $3^{\prime}$ \\
\hline $\mathrm{NH}-3^{\prime}$ & & 9.09 (s) & $\mathrm{H}-8^{\prime}$ & $2^{\prime}, 3^{\prime}, 8^{\prime}$ \\
\hline $\mathrm{NH}-3$ & & $8.31(\mathrm{~d}, 8.0 \mathrm{~Hz})$ & $\mathrm{H}-3$ & $3,7^{\prime}$ \\
\hline $\mathrm{OH}-2^{\prime}$ & & $12.83(\mathrm{~s})$ & & \\
\hline
\end{tabular}

$\mathrm{H}-21$ in ${ }^{1} \mathrm{H}-{ }^{1} \mathrm{H}$ COSY, and by combining the HMBC correlations between $\mathrm{H}-8, \mathrm{H}-19$ and $\mathrm{C}-17$, and between $\mathrm{H}-$ 21 and C-17, C-18 respectively, established the presence of a 2-methyl butanoyl group.

The overall structure of $\mathbf{1}$ was unambiguously established by 2D NMR spectra including COSY, HMQC and HMBC (Table 1 and Fig. 1). This structure was also supported by the mass fragment patterns (Fig. 2).

In 1949, Dunshee et al. first isolated antimycins A from Streptomyces fermentation products [6]. They thought the products were consisted of at least four closely related compounds, differing only in the substituents at the 7- and 8-positions of the dilactone ring. Subsequently Abide et al. isolated the mixture of antimycins $\mathrm{A}$ into eight hitherto subcomponents, A1a, A1b, A2a, A2b, A3a, A3b, A4a and $A 4 b$ by HPLC [7] and identified the structure of Ala by

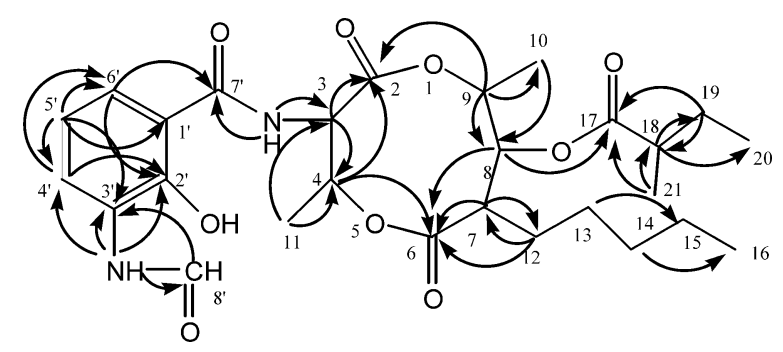

Fig. 1 Selected $\mathrm{HMBC}$ correlations of $\mathbf{1}$.

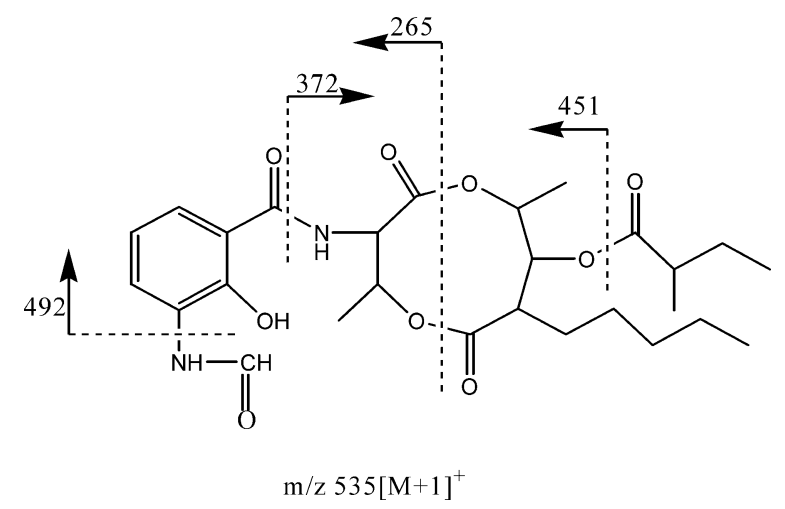

Fig. 2 Selected mass fragments of $\mathbf{1}$.

1D, 2D NMR and X-ray [8, 9]. Tsunoda et al. had accomplished the total synthesis of antimycin $\mathrm{A}_{3 \mathrm{~b}}$ [10]. Compared with known antimycin A series, compound $\mathbf{1}$ is different at the 7-position. In the antimycin A series, the 7-position substituent is $n$-hexyl or $n$-butyl; but in $\mathbf{1}$ is n-pentyl. Thus we can name $\mathbf{1}$ as antimycin $\mathrm{A}_{17}$ [11].

In our present study, a wide range of microorganisms was examined including 12 kinds of representative fungi. It was found that antimycin $A_{17}$ has broad inhibitory activity to microorganisms. Especially to three fungi, Curvularia lunata (Wakker) Boed, Rhizopus nigrtcans Ehrb and Colletotrichum nigrum EL. et Halst antimycins $\mathrm{A}_{17}$ showed more sensitivity (Table 2). The bioassay results suggest that antimycin $\mathrm{A}_{17}$ may be an ideal candidate as a food preservative, pharmaceutical and natural microorganismbased product.

Acknowledgments This work was supported by the National Natural Science Foundation of China (20072058), the 863 Foundation of China (2003AA624010), the Natural Science Foundation of Guangdong Province, China (980317). 
Table 2 The antimicrobial activity study of antimycin $A_{17}$ against 12 fungal strains

\begin{tabular}{|c|c|c|c|}
\hline \multirow{2}{*}{ Fungi } & \multicolumn{2}{|c|}{$\begin{array}{l}\text { Average diameter of radial } \\
\text { growth }(\mathrm{cm})\end{array}$} & \multirow{2}{*}{$\begin{array}{c}\text { Rate of } \\
\text { inhibition* } \\
(\%)\end{array}$} \\
\hline & CK & Treatments & \\
\hline Rhizopus nigrtcans Ehrb & 7 & 3.5 & 50 \\
\hline Geotrichum candidum Link & 6.9 & 6.55 & 5.1 \\
\hline Fusarium oxysporum f.sp. cubense & 4.4 & 4.1 & 6.8 \\
\hline Cladosponum carpophilum Thum. & 3.4 & 3.5 & -2.9 \\
\hline Alternaria solani (E. et M.) Jones et Grout & 5.3 & 3.8 & 28.3 \\
\hline Cladosporium sp. & 1.5 & 1.4 & 66.7 \\
\hline Sclerotinia sclerotiorum (Lib.) de Bary & 2 & 1.5 & 25 \\
\hline Peronophthora litchi Chen & 2.8 & 2.5 & 10.7 \\
\hline Botrytis sp. & 1.4 & 1.2 & 14.3 \\
\hline Colletotrichum nigrum EL.et Halst & 2.8 & 1.4 & 50 \\
\hline Curvularia lunata (Wakker) Boed & 3 & 2.2 & 26.7 \\
\hline Phomopsis vexans (Sacc et Syd) Harter & 2.5 & 2.3 & 8 \\
\hline
\end{tabular}

* Rate of inhibition $\%=[(C K$ average diameter of radial growth-treatments average diameter of radial growth)]/CK average diameter of radial growth $\times 100$.

\section{References}

1. Osada H. Actinomycetes: how fascinating microorganisms. Actinomycetologica 12: 85-88 (1998)

2. Takahashi Y, Ōmura S. Isolation of new actinomycete strains for the screening of new bioactive compounds. J. General Applied Microbiology 49: 141-154 (2003)

3. Miyadoh S. Research on antibiotic screening in Japan over the last decade: a producing microorganism approach. Actinomycetologica 7: 100-106 (1993)

4. Shiomi K, Hatae K, Hatano H, Matsumoto A, Takahashi Y, Jiang CL, Tomoda H, Kobayashi S, Tanaka H, Ōmura S. A new antibiotic, antimycin A9, produced by Streptomyces sp. K01-0031. J Antibiot 58: 74-78 (2005)

5. Barrow CJ, Oleynek JJ, Marinelli V, Sun HH, Kaplita P, Sedlock DM, Gillum AM, Chadwick CC, Cooper R. Antimycins, inhibitors of ATP-citrate lyase, from a Streptomyces sp. J Antibiot 50: 729-733 (1997)

6. Dunshee BR, Leben C, Keitt GW, Strong FM. The isolation and properties of antimycin A. J Am Chem Soc 71: 2436 (1949)

7. Abidi SL. High-performance liquid chromatographic separation of subcomponents of antimycin A. J Chromatography 447: 65-79 (1988)

8. Abidi SL, Adams BR. Proton and carbon-13 resonance designation of antimycin $A_{1}$ by two-dimensional NMR spectroscopy. Magnetic Resonance in Chemistry 12: 10781080 (1987)

9. Kim H, Esser L, Hossain MB, Xia D, Yu CA, Rizo J, Helm $\mathrm{D}$, Deisenhofer J. Structure of antimycin $\mathrm{A}_{1}$, a specific electron transfer inhibitor of ubiquinol-cytochrome $c$ oxidoreductase. J Am Chem Soc 121: 4902-4903 (1999)

10. Tsunoda T, Nishii T, Yoshizuka M, Yamasaki C, Suzuki T, Ito $\mathrm{S}$. A total synthesis of (-)-antimycin $\mathrm{A}_{3 \mathrm{~b}}$. Tetrahedron Letters 41: 7667-7671 (2000)

11. Hosotani N, Kumagai K, Nakagawa H, Shimatani T, Saji I. Antimycins $\mathrm{A}_{10} \sim \mathrm{A}_{16}$, seven new antimycin antibiotics produced by Streptomyces spp. SPA-10191 and SPA-8893. J Antibiot 58: 460-467 (2005) 